\title{
Bridging Class and Field: Field Instructors' and Liaisons' Reactions to Information About Students' Baseline Performance Derived From Simulated Interviews
}

Marion Bogo, Barbara Lee, Eileen McKee, Roxanne Ramjattan, and Stephanie L. Baird

\author{
Version Publisher's PDF \\ Citation Bogo, M., Lee, B., Mckee, E., Ramjattan, R., \& Baird, S. L. (2017). Bridging \\ (published version) Class and Field: Field Instructors' and Liaisons' Reactions to Information \\ About Students' Baseline Performance Derived From Simulated \\ Interviews. Journal of Social Work Education, 53(4), 580-594. \\ doi:10.1080/10437797.2017.1283269 \\ Copyright / License CC BY-4.0 \\ Publisher's Statement This is an Accepted Manuscript of a journal article published by Taylor and \\ Francis in Journal of Social Work Education. The published version is available at \\ https://www.tandfonline.com/doi/full/10.1080/10437797.2017.1283269
}

How to cite TSpace items

Always cite the published version, so the author(s) will receive recognition through services that track citation counts, e.g. Scopus. If you need to cite the page number of the author manuscript from TSpace because you cannot access the published version, then cite the TSpace version in addition to the published version using the permanent URI (handle) found on the record page.

This article was made openly accessible by $U$ of 'T Faculty.

Please tell us how this access benefits you. Your story matters. 


\title{
BRIDGING CLASS AND FIELD
}

\section{Bridging class and field: Field instructors' and liaisons' reactions to information about students' baseline performance derived from simulated interviews}

\begin{abstract}
To strengthen students' preparation for engaging in field learning, an innovation was implemented to teach and assess foundation year students' performance prior to entering field education. An Objective Structured Clinical Examination (OSCE) informed the final evaluation of students' performance in two companion courses on practice theory and skills. The evaluation was used by field instructors and students to develop the field learning plan. This paper reports on a qualitative study that examined field instructors' and faculty field liaisons' experiences and reactions to using this new approach and its impact in shaping students' field learning goals. Implications for supporting adoption of innovations that strengthen the link between classroom and field teaching are offered, including new institutional policies that resulted from ongoing evaluation.
\end{abstract}




\section{BRIDGING CLASS AND FIELD}

\section{Bridging class and field: Field instructors' and liaisons' reactions to information about students' baseline performance derived from simulated interviews}

Providing high quality field education is currently challenging due to a wide range of issues effecting social service and health organizations, higher education, and the social work profession. The economic conditions facing organizations contribute to significant limitations in voluntarily providing social workers as field instructors, especially those who offer intensive educational supervision associated with quality field learning. The Council on Social Work Education (CSWE) convened a national meeting in 2014, the Field Summit, to analyze current conditions and consider possible responses. One recommendation that emerged from the Field Summit was that social work programs identify, teach, and assess "a baseline set of professional expectations and skills" (CSWE, 2015, p. 9) and provide additional classroom learning to support students' when they enter the field. This ensures students are prepared to quickly and successfully engage in field learning (CSWE, 2015).

In an earlier program of research that evaluated students' competence, field instructor respondents argued that schools must take on more responsibility for teaching and assessing basic skills (Author, 2007). In response, the MSW Program at University XXX designed and tested an innovative approach that uses simulation to teach and assess students' practice knowledge and skills prior to students entering the field. A series of studies demonstrated that this innovation was effective in assessing students' competence (Author, 2012).

The next step in the program of research was to develop and evaluate a process to convey this information about students' competence to field instructors so as to provide a bridge between classroom and field learning. The aim was to assist field instructors' efforts to quickly engage with students in developing learning goals and a focused learning plan. This paper reports on the 


\section{BRIDGING CLASS AND FIELD}

process used to bridge learning in these two domains and a study that examined field instructors' and faculty field liaisons' experiences and reactions to using this new approach and its impact in shaping students' field learning goals. Implications for supporting adoption of innovations to strengthen the link between classroom and field teaching are offered, including new institutional policies that resulted from ongoing evaluation.

\section{The Challenge}

The Council on Social Work Education (CSWE) designated field education as the signature pedagogy in social work where students learn to "connect the theoretical and conceptual contribution of the classroom with the practical world of the practice setting" (CSWE, 2008, p. 8). Through pervasive, routine, and habitual educational practices, students are socialized to the essential dimensions of thinking, performing, and acting with integrity, consistent with their particular professions (Shulman, 2005). Social work pedagogical literature based on research and practice wisdom identifies best practices for field education (Author, 2015; Fortune \& Abramson, 1993; Fortune, McCarthy, \& Abramson, 2001; Hendricks, Finch, \& Franks, 2013; Homonoff, 2008; Hunter, Moen, \& Raskin, 2015; Lee \& Fortune, 2013). Despite this knowledge, structural issues in agencies have made it increasingly difficult for field instructors to provide focused time to teach students to function in the agency context, provide effective service, integrate theory and practice, and master social work skills. Documented challenges include more complex cases, fewer agency resources and hence fewer social workers able to be field instructors, especially for students with little practice experience and limited skills. The intensive field supervision model required for beginning students is no longer easily provided by agency social workers (CSWE, 2015; Gursansky \& Sueur, 2011; Hunter et al., 2015). 


\section{BRIDGING CLASS AND FIELD}

While a range of recommendations to strengthen field education is emerging, there is also interest in creating innovative approaches in classroom courses that can better prepare students with foundation skills prior to their beginning field experiences (CSWE, 2015). The expectation is that field instructors would be able to engage beginning students more quickly in learning to apply generic knowledge and practice skills to the populations and issues presented by clients in the particular setting.

This recommendation assumes that students would be able to easily transfer the knowledge learned in classes and interviewing skills labs to practice in organizations and with clients. The notion that transfer of learning from one context to another is a straightforward, automatic, and linear process has been challenged by the educational theorist Michael Eraut. When the new context is complex and unlike the one in which the skills were learned, a new learning process must occur (Eraut, 2003). Knowledge and skills previously acquired must be reexamined and understood in relation to the new context to establish its relevance to address the current situation. Previous knowledge needs to be integrated with new knowledge and often adapted. This perspective appears relevant for social work students who likely have learnt knowledge and skills in practice classes or skills labs but who also need to engage in a learning process to bridge class and field and, to some extent, transform knowledge learned for use in the new context of the agency setting.

In social work, Boitel, Farkas, Fromm, and Hockenstad (2009) and Boitel and Fromm, (2014) were also aware of the challenge in the transfer of knowledge and proposed a model to develop a field learning contract to assist students to integrate learning across the entire curriculum into their field experiences. Drawing on learning theory, Boitel et al. $(2009 ; 2014)$ noted that prior knowledge needs to be subjected to critical thinking and examined to determine 


\section{BRIDGING CLASS AND FIELD}

faulty assumptions. As well, sufficient time is required both to learn and to practice new learning. Field instructors need to explicitly attend to the transfer implications of learning for practice, identify the areas for transfer, and guide students to consider how learning in one context can be used or adapted to the current situation (Boitel et al., 2009). According to Boitel et al. $(2009 ; 2014)$ and similar to Eraut (2003), a process of retrieval and abstraction, generalization, and application of knowledge ensues.

An innovation was developed to address the issues identified in this literature. First, to respond to field instructors' recommendation that social work programs prepare students with foundation practice knowledge and skills prior to beginning field learning. Second, that transfer of learning is not automatic and efforts must be made to assist students to bridge class and field.

\section{An Innovation: Using Simulation to Teach, to Assess Learning, and to Bridge to the Field}

The innovation presented and studied in this paper emerged from an assessment of student learning in two intensive companion courses, a practice theory course and a skills lab, required of all students in the foundation year. The MSW program at University XXX uses a delayed-entry field education model in the foundation year; students are only enrolled in courses in the first semester and begin field education in a concurrent model in the second semester.

Two companion courses are taught in an integrated manner, scheduled on the same day each week for a total of six hours a day. Classes meet every week for 13 weeks. Class sections consist of 18 students each to provide many opportunities for students to practice and to be observed. This format enables the course instructors to teach practice theory, relevant research, and practice behaviors and skills for the beginning stage of practice, relationship formation, and assessment. In addition to short lectures, readings, presentations by social workers and clients, the major pedagogical approach is experiential. Students are actively engaged in applying theory 


\section{BRIDGING CLASS AND FIELD}

and developing practice competence through discussing case studies, reviewing video recordings of experts, extensive practice of skills in role plays with other students, and interviews with standardized actors in simulations of client situations. There is extensive and continuous debriefing and assessment by each student, by peers, and with the instructor in relation to competencies to be achieved.

Social work educators have used role play between students and simulation with trained actors to teach aspects of social work practice in a range of courses, for example in practice in mental health (Badger \& MacNeil, 2002), family therapy (Mooradian, 2007) and interviewing (Petracchi \& Collins, 2006). A developing research literature finds these approaches are well regarded by students and instructors (Author 2013). Moreover, studies show that teaching with simulation appears to enhance competence in assessment of domestic violence (Forgey, Badger, Glibert, \& Hansen, 2013) and in cultural competence (Lu et al., 2011).

The final assignment is an Objective Structured Clinical Examination (OSCE) adapted for social work where students are observed and rated as they conduct a 15 minute interview with a standardized simulated client followed by a written reflection responding to a set of standardized questions which are also rated using a scale (Author 2012; 2014). Used in health professions education to assess students' competence, standardized simulated clients are actors trained to enact scenarios typically encountered by the particular profession (Harden \& Gleeson, 1979; Hodges, Hollenberg, McNaughton, Hanson, \& Regehr, 2014). Standardization of presentation by the actor occurs through continuous training and monitoring of their performance. The interview is rated by a member of the course teaching team other than the course instructor for the particular student. The OSCE ratings and any relevant comments are forwarded to each student's course instructor. These OSCE assessments are incorporated into a 


\section{BRIDGING CLASS AND FIELD}

Social Work Practice Laboratory Evaluation Summary (LES) which also consists of observations and assessments of student learning and performance throughout the semester. The LES identifies students' strengths, areas needing further development, and goals for field learning by using similar competency-based terminology as those used in the field evaluation. Students bring this LES to the field instructor at the beginning of their practicum to identify field learning goals and develop a learning plan.

The aim of these courses and this process is to bridge class and field through teaching foundation knowledge and skills, enhance transfer of learning, focus field learning on specific competencies, and provide useful information to develop the field learning plan. This preparation also aims to decrease students' anxiety and increase confidence and readiness to serve clients they will encounter in agency settings so they can function and learn in the field (Gelman, 2004; Kanno \& Koeske, 2010). Legal consultation was sought and students agree when accepting admission to the program that information about their learning in the course can be shared when they begin field education.

\section{Research Focus}

This paper reports on a study that examined the impact of an innovation used to bridge learning in two companion courses with learning in the field. The study aimed to examine field instructors' and faculty field liaisons' (hereafter referred to as liaisons) experiences and reactions to receiving information about students' competence through the Social Work Practice Laboratory Evaluation Summary (LES), including the OSCE.

\section{Methodology}

The study used a multi-stage qualitative research design that consisted of one-to-one interviews with field instructors, a focus group with faculty field liaisons, and a follow-up online 


\section{BRIDGING CLASS AND FIELD}

survey with field instructors. (See Figure 1). The triangulation of perspectives from field instructors and liaisons provided breadth and depth of responses to enhance the quality of the qualitative data. The follow-up online survey with field instructors provided opportunity for prolonged engagement and repeated contact to enhance trustworthiness in the qualitative study (Anastas, 2004). Data from these instructors was used in the analysis. (See the middle row of process boxes in Figure 1). Ethics approval was obtained from the University's Research Ethics Board to explore the impact of the LES, including the OSCE, on field instructors' and liaisons' educational focus and learning plan with new MSW students.

$<$ Please insert Figure 1 about here $>$

\section{Recruitment and Sample}

Field instructors and liaisons are active participants with the school's Field Education Program and are regularly invited to provide feedback to improve the functioning of the program. Therefore, it was important to obtain their experiences and reactions to the use of the LES, including the OSCE. Field instructors who have provided supervision for students in the first term, first year of the MSW Program, with at least one year of experience, were recruited to participate in the study on a voluntary basis. Field instructors were recruited via phone and email through the school's Field Education Program listserv. Participants did not receive any monetary incentive for their involvement.

Eighteen field instructors participated in the one-on-one interviews. The field instructors were predominately female $(89 \%)$, white $(89 \%)$, with a degree in social work $(95 \%)$ at the masters level (83\%). Fifty-five percent of the field instructors practiced social work in the health, mental health and addictions, $28 \%$ in community social service settings, $11 \%$ in gerontology, and six percent in child welfare. Thirty-nine percent of field instructors had social work practice 


\section{BRIDGING CLASS AND FIELD}

experience for over 20 years and 50\% were supervising students between 1 to 9 years. A majority of them had supervised students after the implementation of the OSCE (61\%).

All faculty field liaisons for foundation year students were recruited and all $(n=8)$ participated in the focus group discussion. The liaisons were predominantly female $(88 \%)$, white (88\%), with an MSW (100\%). Seventy-six percent of liaisons had backgrounds in health, mental health and addiction, with $12 \%$ in each of child welfare, and community social service. Fifty percent of liaisons had social work practice experience between 10 to 19 years and $62 \%$ had supervised students between 1 to 9 years. A majority of the liaisons had supervised over 20 students $(62 \%)$ both prior to and after implementation of the OSCE.

Place Table 1 about here

A brief online survey was sent through the Field Education Program listserv to all 179 field instructors who had provided supervision for students in the first term, first year of the MSW Program since introduction of the innovation. Sixty-eight field instructors (38\%) responded. Due to the technological limitations of the online survey tool, demographic information for the respondents was unattainable.

\section{Research Procedure}

Interviews with field instructors. Questions in a semi-structured interview guide sought to explore field instructors' use of the LES to inform their initial impression of the student and of the student's level of confidence. As well questions sought to elicit instructors' experience in using the LES to develop the learning plan. Additional questions also sought instructors' comparison of students' level of competence in comparison to students they had instructed prior to the program's introduction of the OSCE and the LES. One-on-one interviews of up to one hour were held in a private room at the school or the field instructor's agency. The interviews 


\section{BRIDGING CLASS AND FIELD}

were audio-recorded and transcribed verbatim. Preliminary data analysis suggested that saturation was achieved with the 18 participants, in which no unique responses were derived from the one-to-one interviews.

Data analysis was conducted over two phases using techniques associated with thematic analysis (Braun \& Clarke, 2006) by hand and in NVivo, version 10. The first phase of analysis involved holistic coding by hand and a constant comparative method by all four members of the research team (Saldaña, 2013; Strauss \& Corbin, 1998). Eighteen transcripts were read in their entirety by the research team to gain familiarity with the information and to identify initial patterns in the data. Preliminary themes identified within one interview were compared within and between interviews, to determine whether the same ideas appeared or whether the preliminary themes needed to be further refined (Strauss \& Corbin, 1998). Eighteen transcripts were uploaded into NVivo, version 10 for further analysis.

A second cycle of coding involving structural coding, descriptive coding, and magnitude coding were applied to the qualitative data (Saldaña, 2013). Structural coding segments the data based on the questions and responses in the semi-structured interview guide to identify major categories or themes. Descriptive coding captured and summarized the broader topic of discussion. Magnitude coding was used as a "supplemental shorthand to add texture to codes, subcodes, and categories" (Saldaña, 2013, p. 73). Magnitude coding can also be used to enumerate descriptive data to determine the frequency and strength of responses (Saldaña, 2013). Multiple coders were used to code the data. Two coders worked independently and then met to compare results. Coding decisions were recorded, discussed, and agreed upon by consensus with the broader research team of four members. Further, thematic analysis (Braun \& Clarke, 2006) was conducted to identify common meanings and important issues within the data, which were 


\section{BRIDGING CLASS AND FIELD}

discussed with the entire research team, before proceeding with the next steps of analysis.

Multiple coders, recorded audit-trail, and research team consensus for decision-making was used to enhance trustworthiness of the research study.

An overwhelming discovery was that field instructors needed additional information regarding the purpose and utility of the LES, including the OSCE. Moreover, liaisons play an important role in bridging class and field for new MSW students, and could provide additional depth and breadth of information to this research. As a result, an amendment to the ethics protocol was requested to expand the sampling frame to include liaisons and to conduct a followup survey with field instructors. This sparked two parallel stages of data collection and analyses, represented by the upper and lower process boxes in Figure 1.

Online survey of field instructors. The upper row of process boxes in Figure 1 represents the continued effort to inquire about field instructors' educational focus and learning plan with new MSW students. A set of written and video-recorded materials titled "Bridging Learning in the Class and the Field" (hereafter referred to as materials) was developed and shared via the school's Field Education Program listserv with field instructors and liaisons to provide context, common language, and clarity regarding the LES, including the OSCE. A follow-up online survey was developed and emailed through the school's Field Education Program listserv to field instructors who have provided supervision for students in the first term, first year of the MSW Program. Questions focused primarily on eliciting data about their use of the new materials and whether it was helpful. The final question asked for any comments field instructors wanted to offer about students' readiness for field learning. The online survey responses were collected and stored in a secure XXX server, and extracted and uploaded into NVivo, version 10 for further analysis and to triangulate the data (Denzin, 2012; Flick, 2007). 


\section{BRIDGING CLASS AND FIELD}

Focus group with faculty field liaisons. The bottom row of process boxes in Figure 1 represents the triangulation of data from faculty field liaisons. Active liaisons who have provided support for students in the first term, first year of the MSW Program, were recruited to participate in a focus group on a voluntary basis. Participants did not receive any monetary incentive for their involvement. The semi-structured interview guide that was used with field instructors was modified slightly for use with liaisons. Questions sought to explore liaisons' understanding and use of the new materials, their perception of how field instructors and students used the LES to develop the learning plan, and any additional information about how they used the materials to bridge class and field. The focus group was held in a private meeting room at the school, and lasted approximately one hour. The focus group was audio-recorded and transcribed verbatim.

A similar iterative process of coding and analysis was conducted by hand and then after uploading the focus group transcript into NVivo, version 10. A first phase of analysis used holistic coding by hand and a constant comparative method (Saldaña, 2013; Strauss \& Corbin, 1998). A second cycle of coding involved structural coding, magnitude coding, and descriptive coding (Saldaña, 2013). Finally, thematic analysis (Braun \& Clarke, 2006) was applied to the liaisons' focus group responses. Since similar themes emerged from the analysis of the one-onone interviews and online survey with field instructors, as well as the focus group discussion with liaisons, the data were integrated for an overall interpretation and are presented together in the findings section.

\section{Findings}

This paper reports on field instructors' and liaisons' experiences and reactions to the use of the Social Work Practice Lab Evaluation Summary (LES) when students began their field 


\section{BRIDGING CLASS AND FIELD}

education experience. The themes derived from the one-on-one interviews and online survey with field instructors, as well as the focus group discussion with liaisons include: 1) variability in initial knowledge of the LES/OSCE, 2) establishing baseline competency, 3) pre- and postOSCE requests, 4) ambivalence about the innovation, and 5) recommendations for improvement.

\section{Variability in Initial Knowledge of the LES/OSCE}

While many of the participants in the interviews had at least some initial knowledge of the LES and OSCE at the time of the study, confusion abounded in differentiating between the two. For example, one participant noted “...it's just another piece of paper that you have to use...what's it called? The OSCE." Similarly, another participant indicated, "I looked at the OSCE form". The terms LES and OSCE were almost used interchangeably by many of the participants. One participant described understanding the OSCE as "a semester course...there is a review when they do various role plays throughout, right?" This description however refers to the course from which the LES is generated, including the OSCE as the final assessment.

Variation also existed in how field instructors first learned of the LES/OSCE. Some described learning of the LES/OSCE from communication from the school and others from their students. Timing of this initial knowledge also differed; some participants learned of the LES/OSCE prior to the beginning of term, and others became aware of them several months later. One participant commented on this, stating, "I actually never knew about the OSCE until I went to the Field Instructor meeting." The student was often described as key in transmitting information about the LES and the OSCE, with participants describing their initial knowledge about the OSCE occurring when the student first brought their LES to the field, or when students first reflected on their OSCE experiences. For example, “perhaps if my student hadn’t been forthcoming, I might never have seen the OSCE results or known there was one." Another 


\section{BRIDGING CLASS AND FIELD}

participant indicated “my student came, and she didn't have it so I asked her for it. We talked a bit, and then I think she was a bit anxious about giving me the evaluation, but she brought it, and it was quite positive.”

In response to the variability, written and video-recorded materials were provided to field instructors, however the sheer volume of information shared may have actually worked against promoting understanding. A field instructor commented that "[w]hen you do start a practicum you get a lot of information which you need and it's very valuable, but it's probably easy for it to get buried."

Data from the follow-up online survey validated these reactions as they were similar with respect to variability of initial knowledge of the LES/OSCE. All 179 field instructors received the written and video-recorded materials and the online survey. Sixty-eight responded to the online survey. Of these 68 respondents slightly more than half (59\%) reviewed some or all of it. For those who did not review the materials, $40 \%$ indicated this was due to workload and time constraints, with the remaining unsure whether or not they had even received the materials. For those who reviewed the materials, the majority found it provided greater understanding of the courses (67\%), the OSCE (59\%), and the LES (65\%), while the remaining respondents were uncertain. The majority of field instructor respondents $(63 \%)$ found the materials to be helpful in providing clear connections between competencies in the courses and in the field.

Some liaisons also noted challenges in accessing and understanding the materials. A liaison observed "it got lost in that email with all the information that was there. The email kind of runs through the OSCE and the whole process, but it was just a link out of so much information." Other liaisons valued the extent of materials while admitting it can be "a little 


\section{BRIDGING CLASS AND FIELD}

overwhelming" and "even though I looked at it, I can't retain it" and "I'm on information overload."

Liaisons also varied in their knowledge and understanding of the social work practice courses, the LES and OSCE, the connections between them, and how the materials could be used at the beginning of field learning. For experienced liaisons, the new written and video-recorded materials helped "to visualize the process that the student would go through as far as the OSCE was concerned. I could understand the concept of the OSCE and how it was to be [used] process wise." Another liaison noted that reviewing the LES “displays to the students and to myself that this is an important connection to be made and not simply, how was your last year, what did you do in the summer or some other kind of generalized kind of thing that really needs to be accountable and connect." Liaisons new to the role however revealed their limited understanding of these various components and their need to learn more about them in order to support students and field instructors. For example a liaison commented, "I didn't really know what the course entailed... I didn't really see a connection between the courses and the learning contract, but then I didn't understand the OSCE" and "for new faculty [liaisons] to also have this information is critical if you want to connect that".

\section{Establishing Baseline Competency}

In both the field instructor interviews and written comments on the online survey, field instructors noted that they used both the LES and OSCE to measure baseline competency at the beginning of the field experience. Field instructors revealed that these tools helped them to quickly gather information with regards to students' strengths, weaknesses, previous experiences, and critical thinking skills. A field instructor commented in the interviews, 


\section{BRIDGING CLASS AND FIELD}

Usually at the beginning of the placement the student will bring the OSCE report to me. And because I don't know anything about the student I find it very variable in terms of knowing their strengths, their weaknesses, and areas of improvement for the student. So I will be able to focus more on those areas rather than starting from scratch and assessing myself, so I find it is a very useful tool.

Similarly, a field instructor commented on the survey, "issues identified in the LES have been evident in practice in the field...the LES served to focus discussion and identify learning goals and objectives."

Overwhelmingly, both field instructors and liaisons referred to the OSCE as a “foundation," a "jumping off point," and "a great place to begin." One field instructor described the LES/OSCE as "a starting point for me in just also gauging their level of confidence and some experience." Similarly, another field instructor reflected, "Well, I love the OSCE. I think they're such a good starting point, and it takes a lot of pressure off field instructors. It gives you a head start." By providing a baseline competency, field instructors noted that they were quickly able to focus in areas to work on with students, identifying how even when working with students who did not have much prior experience, the LES/OSCE "helped to identify the learning indicators." Thirty-two (47\%) of the online survey respondents wrote comments indicating that they actively reviewed and used the LES/OSCE at the beginning and often throughout the field.

Interestingly, field instructors also commented on the initial impressions that were formed from students' reflections of their OSCE results. For instance, one field instructor commented, "What I've really valued were her reflections and her insight. That was really helpful for me to get a sense right off the bat of how strong her critical thinking skills were." Similarly, another field instructor commented, "I think my initial impression of the student was 


\section{BRIDGING CLASS AND FIELD}

actually formed in the interview in the fall. Her willingness to bring in the OSCE and to talk about her strengths and weaknesses just gave me respect for her courage and her willingness to be transparent." Therefore, the LES/OSCE was used not only to ascertain baseline competency with regards to strengths and weaknesses, but also a baseline in the student's ability to critically reflect, providing "a better understanding of how they see themselves and their views around any feedback that they might have received."

As well as providing an initial baseline for student competency, the field instructors described how the OSCE provided a measure of student growth throughout the field experience. Field instructors described the value in referring back to the OSCE throughout the semester, with one participant indicating,

We sometimes also look at the OSCEs at the tail end of their placements, together with their evaluations. Students are able to measure their own growth, and I've heard this a lot from them. I thought I knew so much then, but now in regards to doing a retrospective analysis I see how much more I have gained and grown since that OSCE period. Because they do their journaling and everything, they're able to self-reflect on why it is that they rated themselves or saw themselves in a particular place when they did. I think it levels their expectations a bit too for future.

\section{Pre and Post OSCE Requests}

Field instructors identified that additional OSCEs will help measure improvements and overall growth in students throughout their field assignments. Participants commented that "once is not enough" for the OSCE, and suggested that the OSCE be restructured into at least two testing periods, such as pre and post field. This would allow students to receive "feedback at the beginning of the semester then .... [work] on this throughout the semester and improve for the 


\section{BRIDGING CLASS AND FIELD}

last testing," which will "make rich feedback" and "be very different...it would demonstrate really a change in her critical thinking, perspective, growth, and understanding." A field instructor also noted that with a post-OSCE, ...your reflections are different. You see things differently, and maybe you see strengths you didn't realize before or things you would do differently...it's this ongoing process, and it's wonderful that it's happening, but it shouldn't be just limited [to the OSCE]. We should plant the seed that this should happen forever.

When discussing a student's wish for another OSCE, one field instructor paraphrased a student's comment, "You've seen me at my worst when I had no skills at the beginning of practice, but you don't see me at the end even of my first year or my second year."

\section{Ambivalence about the Innovation}

Some field instructors commented on aspects of the OSCE that they did not like, however these comments were often followed by reflections on its usefulness. Thus, a theme that emerged from the analysis was the ambivalence about the innovation as seen in this comment about the OSCE - "It's not perfect, but it gives you a lot of good information." Another participant demonstrated this theme by stating, "I am only picking on the pieces that are negative. There is a good piece of this evaluation that is positive." For instance, a few participants described how they did not find the LES/OSCE overly helpful, but then described how they found the discussion with the student about the experience to be helpful. Thus, one participant described how the OSCE/LES "gave kind of a basis of information but the discussion about it was more helpful than the actual document," while another indicated that "it was an opportunity for discussion as to where [the feedback] was coming from." Thus, the conversation about the 


\section{BRIDGING CLASS AND FIELD}

LES/OSCE feedback was highlighted as useful for field instructors. For example, one participant noted that

ask[ing] the students to reflect on the feedback they had on their experience... was the main useful part because I would always talk to students about what they think they need to learn, areas for growth, what they're bringing to the placement.

Another drawback of the OSCE expressed by some field instructors was that it is too "skill-based," or not as applicable to community-based social work settings. One participant described a view of the OSCE that "it just seemed like it was trying to fit the square peg into the round hole, trying to talk about how she's going to do these various other clinical term things in this very community-based setting." However, these comments were qualified with statements that despite these limitations, the OSCE still provided something useful or important. One field instructor summarized this idea:

But it's tricky because it's not tailored to a population. It's not tailored to a particular kind of counselling. So, it's hard to translate completely into what they were going to need to know. But, I'd hate to see them come in with absolutely nothing in their background. At least, it would give them some degree of confidence if they can see people and meet them and have some idea of what to do.

Another theme that emerged from both field instructors and liaisons was the noted variation in the evaluations; "some of them were quite detailed and showed a real intimate knowledge of the student by the evaluator. Others seemed rather perfunctory and plugged in key words." Generic comments "were difficult to use ... dilutes its usefulness if they are using standard phrases and it's not a more personalized document." However, despite these critiques, [the OSCE] contains information about the student over the course of being in 


\section{BRIDGING CLASS AND FIELD}

communications [practice laboratory] in the fall term. So I find that's often helpful in terms of how the student is [describing] their behaviour throughout the course or perhaps it changes. But how they communicate, how they join in groups, etc. helps to personalize. Therefore, despite some common themes and phrases in the LES/OSCE, field instructors still found them useful, and described how they gained a personalized sense of each student through some of the comments, for example "I already knew that they did not have much experience but it helped to identify the learning indicators which made the initial impression more valuable."

Similarly some liaisons observed that some field instructors thought the content wasn't specific enough to help them pinpoint what exactly students should focus on. However, when the liaison reviewed both the LES and a draft of the learning contract with the student, a rich dialogue ensued where the liaisons were able to facilitate students' attempts at connecting the content in the two documents:

You sit down and have both those papers with them and you look at them together and maybe they brought in a draft of their learning contract...you can make a rich dialogue around this as they explore it themselves and they make the connection with you and you can help facilitate some of those things. That was helpful for me at least.

\section{Recommendations for Improvement}

Without prompting, all participants offered recommendations for improving the OSCE and LES. Field instructor suggestions included more specific goals for field learning, more information about grasping and connecting theory to practice, and more information about students' progress such as a pre and post OSCE, as reflected by one field instructor's comment, "I know with my student we talked about this the other day, and she said she wished there was another [OSCE]" and "they could have benefited from having had multiple people assess them in 


\section{BRIDGING CLASS AND FIELD}

possibly different scenarios because they struggled to generalize." One instructor indicated they "thought that would be helpful part as a supervisor to actually see the OSCE".

Liaisons provided many comments about wanting to improve their knowledge and understanding of the content in the courses and the nature of the LES and the OSCE. For example, one liaison indicated “to even have an idea of what they're learning, what they're reading. That would be helpful." They suggested meetings to receive "the information, understand it and then we can kind of conceptualize it" and "to give it sort of a bit more context may be helpful." Similarly, the field instructors underscored that "there is so much material to cover already" and suggested meetings that focused on this new innovation early in the term with groups of students or groups of instructors, or meetings in person or online with dyads of student and field instructor "to talk about what the two courses were because...you're gearing up for the first meeting with the students and to have a space for that [prior to the student placement] would be great."

\section{Discussion and Implications}

Recognizing the importance in contemporary field education for schools to considerably enhance student preparation with knowledge and skills for rapid engagement with clients and in field learning, this paper described a study of an innovation to bridge class and field. Two companion intensive practice theory and skills courses culminate with an Objective Structured Clinical Examination (OSCE) which was integrated into a Social Work Practice Laboratory Evaluation Summary (LES) which students shared with their field instructor at the beginning of the term. This innovation was developed to enhance student learning and to provide a bridge between class and field. Study findings indicated that generally field instructors and liaisons found that the LES and OSCE was useful to gain an initial understanding of students' 


\section{BRIDGING CLASS AND FIELD}

competence in simulated practice and in determining field goals. Study participants' also highlighted challenges when introducing a new and innovative practice or procedure.

A limitation of the study was the nature of the sample. While every effort was made to include as many field instructors as possible, if there were other participants there might have been different opinions offered about the usefulness of the innovation. Students' perceptions were also not sought in this stage of the study. Since the innovation occurred at only one school, this limits our ability to generalize these findings to other programs. The overall positive response from both field instructors and liaisons however provided a degree of confidence that the efforts to bridge class and field, such as conveying baseline competency about students' performance, may be an efficient way to assist field instructors and students in developing focused field learning contracts.

In order to facilitate transfer of learning, educators note the process needs to begin with assessing prior knowledge (Boitel et al., 2009; 2014). In the field, this typically occurs through reflective discussions between the student and field instructor. While baseline assessments of competence are preferably achieved through observation and review of students' early practice, the literature notes this rarely occurs (Author 2015; Maidment, 2000; Saltzburg, Greene, \& Drew, 2010). The LES provides an alternative approach to accessing such information, even though this information is derived from another context. As Eraut (2003) points out, and supported by some field instructors in this study, the transfer of learning to different and more complex contexts requires engagement in a learning process. When field instructors and liaisons are familiar with both contexts, they are in a position to help students explicitly consider and use the information in the LES to formulate the field learning contract. When they are less familiar however, this can create difficulties as seen with the confusions between the OSCE and the LES. 


\section{BRIDGING CLASS AND FIELD}

The novelty of using simulation to assess student competency seemed to have led some field instructors and liaisons to a greater focus on results from the OSCE rather than the overall evaluation of the student provided in the LES. Even when field instructors were less enthused about the information provided, they believed the LES/OSCE was productive because it stimulated discussion with students about their perceptions of their performance and identified areas for continued learning in the field. Of interest is that instructors who were unfamiliar with both the LES and OSCE simply dismissed this effort to bridge class and field.

Another challenge that emerged in promoting transfer relates to the way terminology is used in social work. It is well known that language used in social work classrooms and in field settings may not always be the same. To bridge class and field, field instructors frequently find themselves faced with learning new terminology. In addition, the terms in competency models may be expressed at a level of abstraction perceived as different from that used in specific agency settings. In an attempt to highlight similar competency elements and practice behaviors, the Field Education office developed materials, especially for field instructors and liaisons. While these communication devices are potentially useful, many participants experienced information overload. With less time for field instruction, reading and understanding additional materials were experienced as burdensome and in some cases simply ignored. Field directors are faced with the challenge of how to efficiently involve field instructors in learning about and using innovations, especially those that are somewhat complex.

Through the various stages of the project, the research team became aware of factors influencing the adoption of this innovation. Those who had created the innovation were immersed in understanding its content and potential to enhance field learning. Hearing the experiences and reactions of the participating field instructors and liaisons highlighted the need 


\section{BRIDGING CLASS AND FIELD}

to enhance their knowledge and understanding of the concepts and related materials, and the challenge of doing this given the lack of time field instructors and liaisons have to devote to these roles.

Initially the program asked students to bring the LES/OSCE to their field instructors. From the very first interviews with field instructors we were surprised that this procedure was enacted in a variable manner; some students followed it, some shared the LES months later, and some made no mention of it whatsoever. Using principles of action research we realized that new procedures were needed to provide scaffolding to support the intention of the innovation. Action research is a form of educational research that "involves learning in and through action and reflection" in order to then take action to improve practice (McNiff \& Whitehead, 2002, p. 28). We immediately made changes to harmonize the conceptualization and language used in the LES and in the field evaluation. Since the competency model underpinning field learning and evaluation were essentially similar to that of the courses, the final LES was re-organized to harmonize and mirror the field competency language. Simply changing documents however is not sufficient. Communication efforts were undertaken with all participants in the relevant domains; the course instructors who wrote the LES/OSCE needed to use the new terminology; faculty field liaisons, field instructors, and students needed to understand the similarities and differences between the competency language and indicators used in simulations and those used in field. Currently most agencies limit field instructors' time for education (Hunter et al., 2015) therefore, as noted earlier, a range of efficient methods of communication were developed including an online video presentation and written materials to augment in-person orientation presentations. Nevertheless these assists could be experienced as an additional demand rather than as helpful. 


\section{BRIDGING CLASS AND FIELD}

Finally, following Eraut's (2003) observation that learners need assistance in understanding the way in which their knowledge and skill is relevant for and can be used in the new context, field instructors were asked to initiate discussion of the LES/OSCE and to incorporate recommendations for learning from that document into the learning contract. A new procedure to ensure accountability involved having the faculty field liaison review the contract to confirm inclusion of the LES suggestions. The next step to enhance bridging and transfer is to focus on these tools in an early field meeting between the faculty field liaison, field instructor, and student.

Upon reflection, diffusion innovation theory helps to further understand the findings from this study as it posits five key factors that influence the process of adoption (Rogers, 2003). New practices, such as using the OSCE/LES, need to be seen as an improvement over current practice and experienced as compatible with the values and needs of the users. These factors appeared to support the use of this new approach. However, the theory notes that the complexity in the new approach is an important factor influencing adoption. Study findings show that confusion in terminology, the time needed to understand the complexity of the LES and OSCE, and the issue of transfer, made the use of information in the LES more difficult to access and use. Ideas that are simpler to understand and use are adopted more easily than those that are more complex. If an innovation can be tried out before a commitment made to use it, this facilitates experimentation. For field instructors who used the information in the LES, even those who were less enthusiastic, found it could enhance engagement in learning and hence, these instructors may be more willing to try to use the tools in subsequent years. Finally, when an innovation provides results which can be easily seen, it is more likely to be adopted. The data in this study confirm this factor. 


\section{BRIDGING CLASS AND FIELD}

\section{Conclusion}

The study findings highlight that even when schools are committed to increasing efforts to increase the preparation of practice competence in foundation year students, transfer of learning between different contexts is not an automatic process. In order to facilitate student learning, instructors in both domains need shared terminology related to competence and also need to understand the complexity of assessment processes and tools. In time-strapped field settings, finding efficient and meaningful ways to encourage adoption of innovations remains a challenge. Studies such as this can provide some insights to further develop social work education practices.

\section{References}

Author $(2007 ; 2012 ; 2013 ; 2015)$.

Anastas, J. (2004). Quality in qualitative evaluation: Issues and possible answer. Research on Social Work Practice, 14(1), 57-65. doi: 10.1177/1049731503257870

Badger, L. W., \& MacNeil, G. (2002). Standardized clients in the classroom: A novel instructional technique for social work educators. Research on Social Work Practice, 12(364-374). doi: 10.1177/1049731502012003002

Boitel, C. R., Farkas, K. J., Fromm, L., \& Hockenstad, M. C. (2009). Learning transfer principles in a comprehensive intergration model. Journal of Teaching in Social Work, 29, 400-417. doi:10.1080/08841230903249687

Boitel, C. R., \& Fromm, L. R. (2014). Defining signature pedagogy in social work education: Learning theory and the learning contract. Journal of Social Work Education, 50(4), 608622. doi: $10.1080 / 10437797.2014 .947161$ 


\section{BRIDGING CLASS AND FIELD}

Braun, V., \& Clarke, V. (2006). Using thematic analysis in psychology. Qualitative Research in Psychology, 3(2), 77-101. doi: 10.1191/1478088706qp063oa

Council on Social Work Education [CSWE]. (2015). Report of the CSWE Summit on Field Education 2014. Alexandria, VA: CSWE. Retrieved from http://www.cswe.org/File.aspx?id=79746

Council on Social Work Education [CSWE]. (2008). Educational Policy and Accreditation Standards (Rev.ed.). Retrieved from http://www.cswe.org/File.aspx?id=13780

Denzin, N. K. (2012). Triangulation 2. Journal of Mixed Methods Research 6 (2), 80-88. doi: $10.1177 / 1558689812437186$

Eraut, M. (2003). Transfer of knowledge between education and the workplace. Nederland: Open Universitaid. Retrieved from: http://www.ou.nl/Docs/Expertise/OTEC/Publicaties/els\%20boshuizen/deel3.pdf

Flick, U. (2007). Designing Qualitative Research. London, UK: Sage Publications.

Forgey, M. A., Badger, L., Glibert, T., \& Hansen, J. (2013). Using standarized clients to train social workers in intimate partner violence assessment. Journal of Social Work Education, 49, 292-306. doi: 10.1080/10437797.2013.768482

Fortune, A. E., \& Abramson, J. S. (1993). Predictors of satisfaction with field practicum among social work students. The Clinical Supervisor, 11(1), 95-110. doi: 10.1300/J001v11n01_07

Fortune, A. E., McCarthy, M., \& Abramson, J. S. (2001). Student learning processes in field education: Relationship of learning activities to quality of field instruction, satisfaction, and performance among MSW students. Journal of Social Work Education, 37(1), 111 124. doi: $10.1080 / 10437797.2001 .10779040$ 


\section{BRIDGING CLASS AND FIELD}

Gelman, C. R. (2004). Anxiety experienced by foundation-year MSW students entering field placement: Implications for admissions, curriculum, and field education. Journal of Social Work Education, 40(1), 39-54. doi: 10.1080/10437797.2004.10778478

Gursansky, D., \& Sueur, E. L. (2011). Conceptualizing field education in the twenty-first century: Contradictions, challenges and opportunities. Social Work Education, 31(7), 914-931. doi: $10.1080 / 02615479.2011 .595784$

Harden, R. M., \& Gleeson, F. A. (1979). Assessment of clinical competence using an observed structured clinical examination. Medical Education, 13, 41-47.

Hendricks, C. O., Finch, J. B., \& Franks, C. L. (2013). Learning to teach: Teaching to learn (2nd ed.). Alexandria, VI: Council on Social Work Education Press.

Hodges, B., Hollenberg, E., McNaughton, N., Hanson, M. D., \& Regehr, G. (2014). The psychiatry OSCE: A 20-year retrospective. Academic Psychiatry, 38, 26-34. doi: $10.1007 / \mathrm{s} 50596-013-0012-8$

Homonoff, E. (2008). The heart of social work: Best practitioners rise to challenges in field instruction. The Clinical Supervisor, 27(2), 135-169. doi: 10.1080/07325220802490828

Hunter, C. A., Moen, J. K., \& Raskin, M. S. (Eds.). (2015). Social work field directors: Foundations for excellence. Chicago, IL: Lyceum.

Kanno, H., \& Koeske, G. F. (2010). MSW students' satisfaction with their field placements; The role of preparedness and supervision quality. Journal of Social Work Education, 46(1), 23-38. doi: 10.5175/JSWE.2010.200800066

Lee, M., \& Fortune, A. E. (2013). Do we need more "doing" activities or "thinking" activities in the field practicum? Journal of Social Work Education, 49(4), 646-660. doi: $10.1080 / 10437797.2013 .812851$ 


\section{BRIDGING CLASS AND FIELD}

Lu, Y. E., Ain, E., Chamorro, C., Chang, C., Feng, J. Y., Fong, R., .. . Yu, M. (2011). A new methodology for assessing social work practice: the adaptation of the objective structured clinical evaluation (SW-OSCE). Social Work Education, 30(2), 170-185. doi. $10.1080 / 02615479.2011 .540385$

Maidment, J. (2000). Methods used to teach social work students in the field: A research report from New Zealand. Social Work Education, 19(2), 145-154. doi: $10.1080 / 02615470050003520$

McNiff, J., \& Whitehead, J. (2002). Action research: Principles and practice (2nd ed.). New York, NY: RoutledgeFalmer.

Mooradian, J. K. (2007). Simulated family therapy interviews in clinical social work education. Journal of Teaching in Social Work, 27(1/2), 89-104. doi: 10.1300/J067v27n01_06

Petracchi, H. E., \& Collins, K. S. (2006). Utilizing actors to simulate clients in social work student role plays: Does this approach have a place in social work education? Journal of Teaching in Social Work, 26(1/2), 223-233. doi: 10.1300/J067v26n01_13

Rogers, E. M. (2003). Diffusion of innovations. New York, NY: Free Press.

Saldaña, J. (2013). The coding manual for qualitative researchers. Thousand Oaks, CA: SAGE Publications.

Saltzburg, S., Greene, G. J., \& Drew, H. (2010). Using live supervision in field education: Preparing social work students for clinical practice. Families in Society, 91(3), 293-299. doi: $10.1606 / 1044-3894.4008$

Shulman, L. S. (2005). Signature pedagogies in the profession. Daedalus, 134(3), 52-59. doi:10.1162/0011526054622015 


\section{BRIDGING CLASS AND FIELD}

Strauss, A., \& Corbin, J. (1998). Basics of Qualitiative Research Techniques and Procedures for Grounded Theory ( $2^{\text {nd }}$ ed.). London, UK: Sage Publications. 


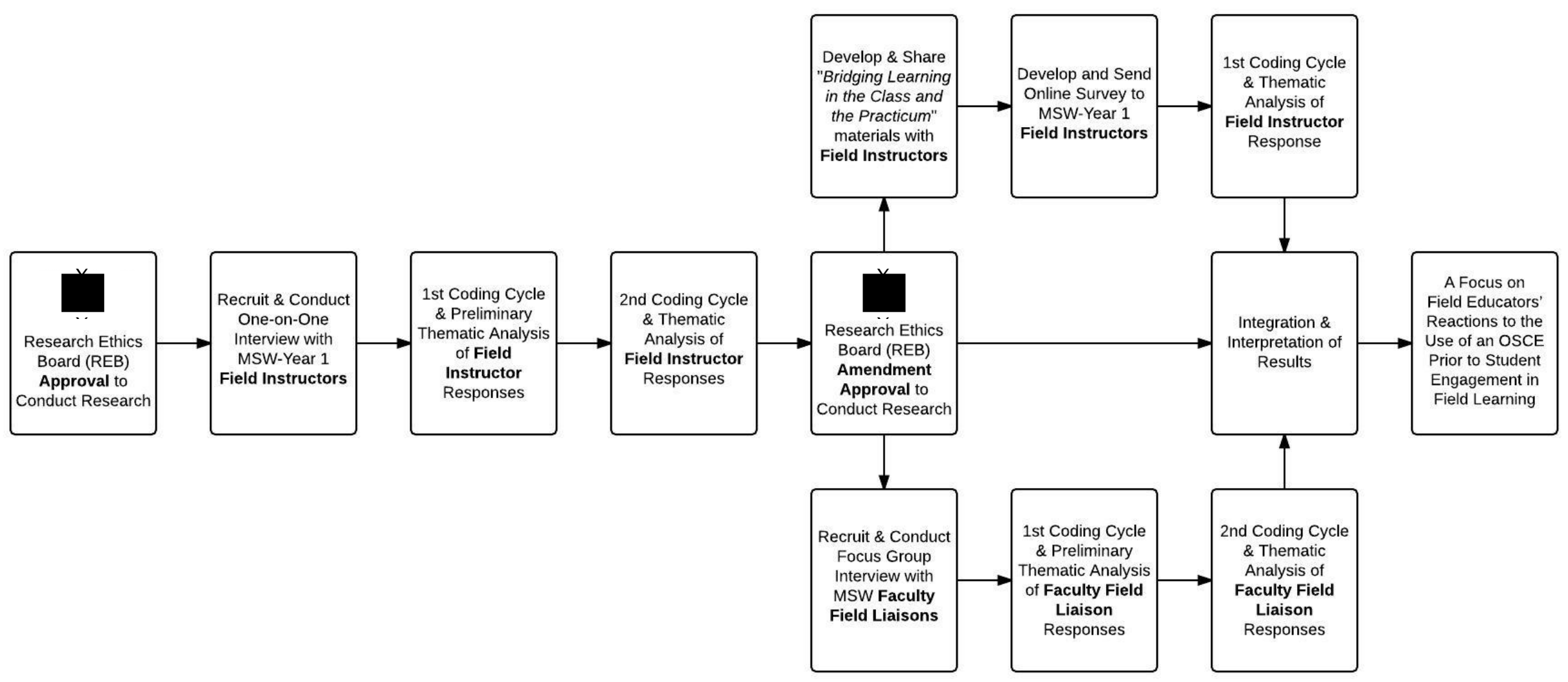


Table 1. Demographic Information on Field instructors $(n=18)$ and Faculty Field

$$
\text { Liaisons }(n=8)
$$

\begin{tabular}{|c|c|c|c|c|}
\hline \multirow[t]{2}{*}{ Demographic Information } & \multicolumn{2}{|c|}{ Field instructors } & \multicolumn{2}{|c|}{ Faculty Field Liaisons } \\
\hline & $n$ & $\%$ & $n$ & $\%$ \\
\hline \multicolumn{5}{|l|}{ Gender } \\
\hline Male & 2 & 11 & 1 & 12 \\
\hline Female & 16 & 89 & 7 & 88 \\
\hline \multicolumn{5}{|l|}{ Ethno-racial Identity } \\
\hline White & 16 & 89 & 7 & 88 \\
\hline Asian & 1 & 6 & & \\
\hline South Asian & 1 & 6 & & \\
\hline Caribbean & & & 1 & 12 \\
\hline \multicolumn{5}{|l|}{ Highest Educational Attainment } \\
\hline Bachelor & 1 & 6 & & \\
\hline Master & 15 & 83 & 8 & 100 \\
\hline $\mathrm{PhD}$ & 2 & 11 & & \\
\hline \multicolumn{5}{|l|}{ Social Work Degree } \\
\hline Yes & 17 & 95 & 8 & 100 \\
\hline \multicolumn{5}{|l|}{ Years of Social Work Practice Experience } \\
\hline$<1$ & 1 & 6 & & \\
\hline 1 to 9 & 4 & 22 & 1 & 12 \\
\hline 10 to 19 & 5 & 28 & 4 & 50 \\
\hline$\geq 20$ & 7 & 39 & 3 & 38 \\
\hline Missing & 1 & 6 & & \\
\hline \multicolumn{5}{|l|}{ Current Field of Service in Social Work } \\
\hline Child Welfare & 1 & 6 & 1 & 12 \\
\hline Health, Mental Health \& Addiction & 10 & 55 & 6 & 76 \\
\hline Gerontology & 2 & 11 & & \\
\hline Community Social Service & 5 & 28 & 1 & 12 \\
\hline \multicolumn{5}{|l|}{ Years Supervising Students } \\
\hline 1 to 9 & 10 & 56 & 5 & 62 \\
\hline 10 to 19 & 6 & 33 & 1 & 12 \\
\hline$\geq 20$ & 2 & 11 & 2 & 25 \\
\hline \multicolumn{5}{|l|}{ Number of Students Supervised } \\
\hline 1 to 9 & 9 & 50 & 3 & 38 \\
\hline 10 to 19 & 3 & 17 & & \\
\hline$\geq 20$ & 6 & 33 & 5 & 62 \\
\hline \multicolumn{5}{|l|}{ Number of Participants who } \\
\hline $\begin{array}{l}\text { Supervised students after the } \\
\text { implementation of the OSCE }\end{array}$ & 11 & 61 & 3 & 38 \\
\hline $\begin{array}{l}\text { Supervised students both prior and } \\
\text { after implementation of the OSCE }\end{array}$ & 7 & 39 & 5 & 62 \\
\hline
\end{tabular}

